\title{
EFFECT OF STORAGE AND PRESERVATION OF HORSE FAECAL SAMPLES ON THE DETECTABILITY AND VIABILITY OF STRONGYLID NEMATODE EGGS AND LARVAE
}

\author{
EWELINA JAGŁA, JUSTYNA ŚPIEWAK, GRZEGORZ ZALEŚNY ${ }^{1}$, AND MARCIN POPIOŁEK ${ }^{1}$ \\ Department of Horse Breeding and Riding, Institute of Animal Breeding, \\ ${ }^{1}$ Department of Invertebrate Systematics and Ecology, Institute of Biology, \\ Wroclaw University of Environmental and Life Sciences, 51-631 Wroclaw, Poland \\ marcin.popiolek@up.wroc.pl
}

Received: October 21, 2012

Accepted: May 15, 2013

\begin{abstract}
The aim of the study was to assess selected methods of storage and preservation of horse faecal samples on the detectability of eggs and survival rate of larvae of strongylid nematodes. Physical and chemical factors were found to have a significant effect on the egg detectability and survival of the larvae. The comparison of control and variously preserved samples revealed that each storage method affected the reliability of the results to some extent. Short-lasting, three-day freezing resulted in a decrease of detectability from $100 \%$ to $94.1 \%$, with an equally significant decrease in the mean number of eggs per one gram of faeces, from $1,238.97$ to 983.82. Extending the freezing period from 3 to $14 \mathrm{~d}$ had a highly significant effect on the prevalence, which was then $85.3 \%$, while the EPG (eggs per gram) value decreased more than twice, compared to control samples, and was 503.68. Thirty-day freezing had no further effect on the parasitological indices, which did not differ significantly from those obtained after a fortnight of freezing. Storing samples in $4 \%$ formalin and $40 \%$ ethanol had a significantly more negative effect on the detectability of strongylid eggs. The prevalence in alcohol-preserved samples was $91.2 \%$ and the EPG was 247.79; the values for formalin-preserved samples were $88.2 \%$ and 153.68. The way of preserving faecal samples was also found to affect the viability of strongylid larvae.
\end{abstract}

Key words: horses, faecal samples, storage methods, Strongylidae.

In recent years, control of parasite invasions in horses has mainly consisted of regular and routine deworming, often using the same or similar pharmacological veterinary medicinal products $(3,15)$. As a result, some helminths - e.g. cyathostomines (Nematoda, Cyathostominae), have become drugresistant, and at present can be no longer controlled using the widespread benzimidazole compounds and pyrantel salts (10). Moreover, since the breeder is usually unable to tell which animals are infected, all the horses are subjected to deworming irrespective of whether they are parasite-free or infected only to a slight degree (3).

Taking these facts into consideration, from horse breeders and veterinarians' point of view, parasitological examination appears to be not only justified but also necessary. Post-mortem examination enables to assess the degree of invasion and to identify the parasite species (13). However, coproscopy is much more practical, quicker and cheaper for a horse breeder; making it possible to ascertain the basic indices of infection in vivo, including the number of parasite eggs per one gram of faeces (EPG). The obtained EPG values not only enable to estimate the degree of helminth infection in the examined animal; they are also useful in identifying and diagnosing horses with suspected parasitoses $(1,5,19)$. Fresh faeces, obtained from the colon or bedding, are an ideal material for such analyses. In practice, however, analysis of fresh faeces is not always possible. Although many studies have dealt with comparisons of various techniques used in assessing the number of eggs in the faeces $(6,4,21,22,28)$, there are still very few reports on the methods of proper storage and processing of the samples prior to laboratory analysis. Several methods of faecal sample preservation are used in practice; enabling to analyse the material not only directly after collection. These methods include storage at low temperatures $\left(4^{\circ} \mathrm{C}\right.$ or $\left.-20^{\circ} \mathrm{C}\right)$ and preservation in solutions of alcohol $(40 \%-70 \%)$ or formalin (4\% and 10\%). However, such procedures may have a negative effect on the detectability of dispersion forms of parasites in the sample tested. The pertinent literature includes several publications on the effect of various faecal preservation methods on the results of coproscopic examination of various animal taxa, namely wild (7) and domestic ruminants (16), as well as horses $(20,25)$. Except for Foreyt's (7) study, which considers the effect of low temperatures, as well as chemical 
preservatives on the detectability of helminth eggs, other papers only deal with the effects of different temperatures (room, low, and negative) on the material with respect to eggs (20) or survival rate of larvae (25). There are no studies that would comprise complex analysis of the effect of physical and chemical factors on the suitability of faecal material for the purposes of parasitological diagnostics. This pertains especially to horses, which, being of practical and economic importance, are of interest to many social groups.

The objective of the paper was to assess the effect of selected methods of preservation of horse faecal samples on the egg detectability and larval viability of strongylid nematodes, and to indicate the simplest and the least biased method, which could be used by horse breeders and veterinarians.

\section{Material and Methods}

Stable. Shetland and Welsh ponies from a private stud farm located on the outskirts of Wroclaw (SW Poland) served as the source of the material. The animals were stabled in boxes with deep bedding and used common pastures and enclosures. The basic feed was oats, hay, and pasture grass. The group of the horses was uniform with respect to age structure and sex ratio, and not subjected to any deworming procedures for two last years.

Experiment. Fresh faecal samples of $300 \mathrm{~g}$, originating from 34 horses, were taken directly from the bedding into plastic containers; each sample was then divided into six equal parts. One series, treated as control, was subjected to laboratory examination directly after sampling, in order to determine the number of strongylid eggs in one gram of faeces (EPG). Each of the remaining five series of samples was subjected to processing with different techniques: $3-\mathrm{d}, 14-\mathrm{d}$, and 1month freezing at $-19^{\circ} \mathrm{C}$ (experiment $\mathrm{A}$ ), and storage in $4 \%$ formalin and $40 \%$ alcohol solutions (experiment B) during 2 weeks. In case of formalin and alcohol, faecal samples were immersed into the preservatives without homogenisation. Additionally, larvae from five selected samples of each series were reared till stage L3 (experiment C) on special mineral substrate-vermiculite (produced by weathering or hydrothermal alteration of biotite or phlogopite), which enables to obtain $60 \%-70 \%$ of larval material in the laboratory culture (9).

Laboratory analysis. Coproscopic analysis for the presence of helminth eggs was done with McMaster's method modified according to Roepstroff and Nansen (24); at present it is regarded as one of the most sensitive and reliable techniques (28). Four-gram portions were mixed with $28 \mathrm{~mL}$ of tap water. Following straining through a sieve, $10 \mathrm{~mL}$ of the resulting suspension were poured into a tube and centrifuged during $5 \mathrm{~min}$ at $1,200 \mathrm{revolutions} / \mathrm{min}$. Then, the supernatant was decanted, and $4 \mathrm{~mL}$ of floatation reagent (saturated $\mathrm{NaCl}$, solution specific gravity: 1.3 ) were added to the sediment. The content of the tube was stirred gently and two chambers of McMaster's plate were filled with it. The plate was left to stand for $5 \mathrm{~min}$, and the eggs in both chambers were counted under the microscope. EPG was calculated by multiplying the sum of eggs from both chambers by 25 . In order to obtain strongylid larval stages, $4 \mathrm{~g}$ of faeces were mixed with $10 \mathrm{~mL}$ of vermiculite and $8 \mathrm{~mL}$ of water. This prepared mixture was kept at $24-28^{\circ} \mathrm{C}$ and proper humidity during $7 \mathrm{~d}$. Then, the larvae were obtained using the classical larvoscopic method of Baermann. Large strongyles and cyathostomines were identified based on their morphology (number and shape of intestinal cells) and biometrics of the third-stage larvae (2). Besides the mean EPG and maximum and minimum values, the prevalence was also calculated as the ratio of positive samples to the total number of samples.

Statistical analysis. Statistical analysis of the results included the qualitative (presence/absence of helminth infection) and quantitative (EPG values) data. Cochran's Q test was used to reveal differences in the prevalence of helminths in the faecal samples stored under different conditions. Friedman's ANOVA was applied to verify the hypothesis on the effect of storage conditions on the estimated level of infection expressed as EPG. Additionally, the effect of freezing of faeces on the viability and detectability of strongylid larvae was analysed with the same statistical tools. All the statistical analyses were performed with software Statistica 9.1.

\section{Results}

Laboratory analysis of 34 samples of the control series showed that the general prevalence of strongylid infection among the horses was $100 \%$ and the mean number of eggs per $1 \mathrm{~g}$ of faeces (EPG) was 1,238.97. In comparison with the results from the control samples, each of the tested storage methods affected the reliability of the obtained results to a greater or lesser extent.

Experiment A: freezing time vs. EPG. The time of freezing of faecal samples was found to have a significant effect on the results $(\mathrm{Q}=9.00 ; \mathrm{P}=0.029$; $\left.\chi_{\mathrm{A}}^{2}=57.308 ; \mathrm{P}<0.001\right)$. A 3 -d freezing resulted in a decrease in detectability from $100 \%$ to $94.1 \%$, and a simultaneous decrease in the number of eggs per $1 \mathrm{~g}$ of faeces from 1,238.97 (range: 525-2,325) to 983.82 (251,825). Extending the freezing period from 3 to $14 \mathrm{~d}$ proved to have a highly significant effect on the level of prevalence, which dropped to $85.3 \%$, whereas the EPG value decreased more than two times compared to the control samples and was $503.68(25-1,575)$. Storage of the samples at low temperatures during $30 \mathrm{~d}$ had no greater effect on the parasitological indices, which did not differ much from those obtained after a fortnight freezing: the detectability was the same $-85.3 \%$ and a decrease in EPG was slight - its value dropped to 491.91 (Table 1, Fig. 1A).

Experiment B: ethanol and formalin vs. EPG. Preservation of the samples in $4 \%$ formalin and $40 \%$ alcohol solutions had a significantly more negative effect on the detectability of strongylid eggs. 
Table 1

Effect of storage and preservation of horse faecal samples on the detectability of strongylid nematode eggs

\begin{tabular}{lcrc}
\hline \multirow{2}{*}{ Storage methods } & \multirow{2}{*}{ Prevalence (\%) } & \multicolumn{2}{c}{ EPG } \\
\cline { 3 - 4 } & & Mean \pm SD & Min-max \\
\hline Control & 100.0 & $1,238.97 \pm 529.66$ & $525-2,325$ \\
\hline Freezing (3 d) & 94.1 & $983.82 \pm 571.28$ & $25-1,825$ \\
\hline Freezing (14 d) & 85.3 & $503.68 \pm 359.09$ & $25-1,575$ \\
\hline Freezing (30 d) & 85.3 & $491.91 \pm 341.38$ & $50-1,125$ \\
\hline $40 \%$ ethanol (after 14 d) & 91.2 & $247.79 \pm 181.88$ & $25-675$ \\
\hline $4 \%$ formalin (after 14d) & 88.2 & $153.68 \pm 12.57$ & $25-600$ \\
\hline
\end{tabular}

Table 2

Effect of storage and preservation of horse faecal samples on the detectability of strongylid nematode larvae

\begin{tabular}{lccc}
\hline \multirow{2}{*}{ Storage methods } & \multicolumn{3}{c}{ Mean number of isolated larvae } \\
\cline { 2 - 4 } & $\begin{array}{c}\text { Cyathostominae } \\
\text { gen sp. }\end{array}$ & $\begin{array}{c}\text { Strongylus equinus } \\
\text { Strongylus } \\
\text { edentatus }\end{array}$ \\
\hline Control & $135.2(118-156)$ & $2(1-8)$ & $0.4(1)$ \\
\hline Freezing (3 d) & $68(6-111)$ & -- & $0.2(1)$ \\
\hline Freezing (14 d) & $1.0(5)$ & -- & -- \\
\hline Freezing (30 d) & $1.2(6)$ & -- & -- \\
\hline $40 \%$ ethanol (after 14 d) & $0.4(2)$ & -- & -- \\
\hline $4 \%$ formalin (after 14 d) & -- & -- & \\
\hline
\end{tabular}
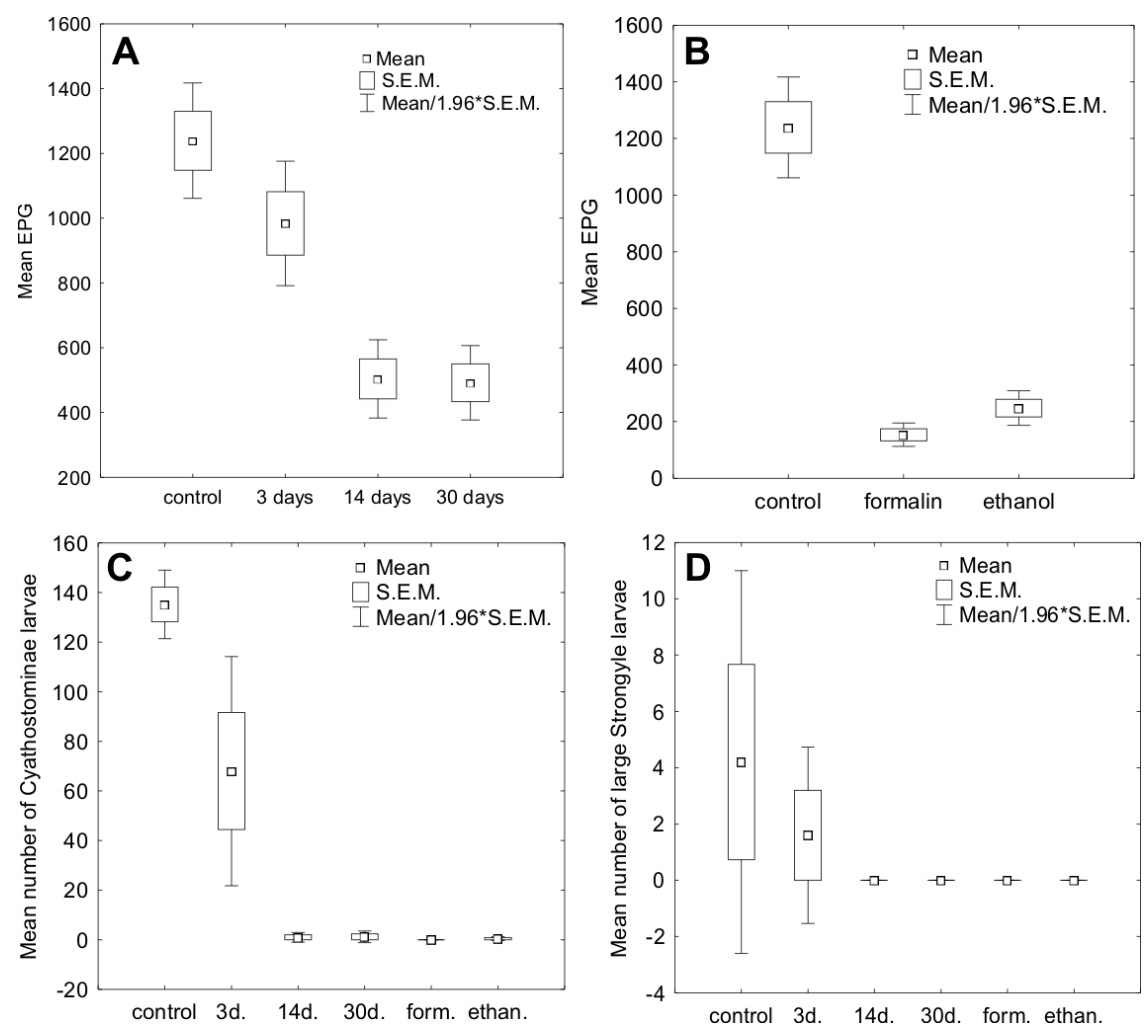

Fig. 1. The effect of storage and preservation of horse faecal samples on the recovery and detectability of strongyle eggs and larvae. A - freezing over time vs. EPG; B - ethanol and formalin vs. EPG; C - freezing, ethanol and formalin vs. Cyathostominae larvae; D - freezing, ethanol and formalin $v s$. large strongyle larvae 
Though, the obtained prevalence was close to that from the previous experiment $(\mathrm{Q}=6.00 ; \mathrm{P}=0.049)$, a decrease in EPG was very pronounced $\left(\chi_{\mathrm{A}}^{2}=54.527\right.$; $\mathrm{P}<0.001)$.

The prevalence for the alcohol-preserved samples was $91.2 \%$, and EPG - 247.79; the respective values for the formalin-preserved samples were $88.2 \%$ and 153.68 (Table 1, Fig. 1B).

Experiment C: sample preservation vs. development rate of strongylid eggs and viability of larvae. The way of preserving faecal samples was found to affect the viability of strongylid eggs (Table 2 and Fig. 1C, 1D). Though the data were obtained only from five randomly selected samples of each series, the results seem to be conclusive. Compared to the control samples, 3-d freezing reduced the mean number of live cyathostomine larvae by half (from 135.2 to 68.0).

Longer freezing had a considerably greater effect on the results $\left(\mathrm{Q}=17.325 ; \mathrm{P}=0.004 ; \chi_{\mathrm{A}}^{2}=21.408\right.$; $\mathrm{P}<0.001)$. After 14 and $30 \mathrm{~d}$ of freezing, rearing of larvae, and their isolation in the Baermann apparatus yielded the mean numbers of 1.0 and 1.2 of live larva, respectively. In case of chemical preservatives (alcohol and formalin), only14-d storage in $40 \%$ alcohol enabled to isolate the mean number of 0.4 live larva, while the effect of formalin was completely lethal to the eggs. In the case of large strongylids, which occurred in small numbers even in the control samples, only single larvae of Strongylus edentatus could be isolated from the samples subjected to $3-\mathrm{d}$ freezing $(\mathrm{Q}=12.222 ; \mathrm{P}=0.032$; $\left.\chi_{\mathrm{A}}^{2}=13.182 ; \mathrm{P}<0.022\right)$.

\section{Discussion}

The experiments revealed a significant effect of physical and chemical factors on the detectability and viability of strongylid eggs and larvae. Nematodes are characterised by relatively short life cycles. Their eggs are expelled with faeces, and at an adequate temperature $\left(18-25^{\circ} \mathrm{C}\right)$ and humidity, invasive larvae develop in the pasture within a few days (8). The development of larvae from stage L1 to the invasive stage L3 takes place outside the egg, as opposed to geohelminths, e.g. Parascaris equorum, where L3 larva leaves the egg only inside the host's organism. Strongylid eggs have thinner envelopes than the eggs of typical geohelminths, which may be of importance for the effect of variable environmental conditions $(12,14)$. This fact might account for the great differences in the EPG between the control and experimental samples. Until now, available data on the influence of various methods of faecal samples preservation on their suitability for future diagnostics have been scarce $(7,16,20,25)$. The most comprehensive analysis was conducted by Foreyt (7). The author analysed the effect of physical (low temperature) and chemical (formalin and ethyl alcohol) conditions on the detectability of eggs and larvae of nematodes in deer. He has found that the best preservation method for long-term storage of faecal samples was $10 \%$ formalin solution; after $200 \mathrm{~d}$, the detectability was still at the level of $50 \%$. When the storage time and formalin concentration were the same as in this study (14 d and 5\%), the extensity of infection was $c a .70 \%$, thus comparable with our results $(88 \%)$. Formalin at various concentrations is widely used in various branches of medicine, including diagnostics in its broad sense. At the concentration of $5 \%$, being a strong bactericide, it is suitable for preservation of anatomical and other biological materials. It is also used as preservative in coproscopic studies, though mainly for more resistant eggs of typical geohelminths, e.g. nematodes of the genera Ascaris, Bayliascaris, Toxocara, or Trichuris (11, 17, 18, 23, 26, 27). In case of thinner-enveloped eggs of parasites, including strongylids, its use has an effect on the obtained results. When the formalin-preserved faeces are only subjected to qualitative analysis, such as species identification, this way of preservation seems to be sufficient and acceptable. For analysis of strictly quantitative parameters, for example the mean number of parasite eggs per $1 \mathrm{~g}$ of faeces, the effect of formalin is no longer negligible. This was confirmed by the results, unambiguously showing the adverse effect of the solution on the detectability of strongylid eggs, since the EPG values decreased from the initial level of 1,238 to only 153 , making the faecal sample less suitable for parasitological examination. The differences observed when $40 \%$ alcohol was used, were also highly significant; the solution had a negative effect on strongylid eggs and caused a decrease in their number per $1 \mathrm{~g}$ of faeces. The experiment showed a decrease in the EPG value to 247 in the experimental series, which, compared to the control samples (1,238 EPG), was of a great significance for the reliability of the parasitological indices.

Different results were obtained in case of the effect of physical factors (freezing). The prevalence of strongylid eggs after $3 \mathrm{~d}(94 \%), 2$ weeks (84\%), and 1 month (84\%) was comparable to the initial level. In contrast, in Foreyt's (7) studies, the storage of samples at $-20^{\circ} \mathrm{C}$ during a week caused a decrease in egg detectability to $15 \%$. The effect of low temperatures on the detectability of nematode eggs was also analysed by Nielsen et al. (20); in an experiment conducted in two sets of climatic conditions, the authors subjected faecal samples to freezing at $-10^{\circ} \mathrm{C}$ for periods ranging from 6 $\mathrm{h}$ to $120 \mathrm{~h}$. In the experiment, conducted in the USA, the EPG value decreased successively with increasing duration of freezing period, from the original level of 260 to the level of 125 eggs per $1 \mathrm{~g}$ of faeces. A similar experiment conducted in Denmark, which differed only in the freezing temperature that ranged from $-18.3^{\circ} \mathrm{C}$ to $-16.8^{\circ} \mathrm{C}$, provided results, which were similar to ours. Nielsen et al. (20) recorded a decrease in EPG from 300 to 200 during the first $24 \mathrm{~h}$ of freezing, and then the level was maintained until the $120^{\text {th }} \mathrm{h}$ of the experiment. In the conducted studies with the freezing temperature equal to $-19^{\circ} \mathrm{C}$, the EPG values decreased distinctly till the $14^{\text {th }} \mathrm{d}$ of freezing $\left(336^{\text {th }} \mathrm{h}\right.$ of experiment), and then no significant decrease was recorded till the end of the experiment.

In other studies $(16,25)$, the effect of temperature on the survival rate of larvae in domestic and wild ruminants was analysed. The results indicated 
that the development of nematode larvae at low temperatures becomes much decelerated and in some species even inhibited. Our studies confirm these results: the 3-d freezing resulted in a $50 \%$ decrease in the detectability of live larvae, and extension of the freezing time resulted in practically complete inhibition of their development. It is interesting that live larvae could be reared in faeces kept in 40\% alcohol even after $14 \mathrm{~d}$.

The results of the experiments, as well as those obtained by other authors, suggest that in the absence of possibility of immediate coproscopic examination of fresh horse faeces, the most reliable and least biased method, which enables to perform quantitative analysis, is short-term freezing or cool-room storage of the faecal sample. Chemical preservation should be considered only when the short-term use of low temperatures is impossible.

\section{References}

1. Becher A.M., Mahling M., Nielsen M.K., Pfister K.: Selective anthelmintic therapy of horses in the Federal states of Bavaria (Germany) and Salzburg (Austria): an investigation into strongyle egg shedding consistency. Vet Parasitol 2010, 171, 116-122.

2. Bowman D.D., Lynn R.C., Eberhard M.L.: Georgis' Parasitology for Veterinarians. Elsevier Science, St. Louis, USA, 2003.

3. Comer K., Coles G.C., Hillyer M.H.M.: A national survey for anthelmintic resistant nematodes in thoroughbreds. Eighteenth International Conference of the World Association for the Advancement of Veterinary Parasitology. Stresa, Italy, 2001, p. 166.

4. Cringoli G., Rinaldi L., Veneziano V., Capelli G., Scala A.: The influence of flotation solution, sample dilution and the choice of McMaster slide area on the reliability of the McMaster technique in estimating the faecal egg counts of gastrointestinals strongyles and Dicrocoelium dendriticum in sheep. Vet Parasitol 2004, 123, 121-131.

5. Döpfer D., Kerssens C.M., Meijer Y.G., Boersema J.H., Eysker M.: Sheeding consistency of strongyle-type eggs in Dutch boarding horses. Vet Parasitol 2004, 124, 249258

6. Egwang T.G., Slocombe J.O.D.: Evaluation of the Cornell-Wisconsin centrifugal flotation technique for recovering trichostrongylid eggs from bovine feces. Can J Comp Med 1982, 46, 133-137.

7. Foreyt W.: Recovery of nematode eggs and larvae in deer: evaluation of fecal preservation method. J Am Vet Med Assoc 1986, 9, 1065-1067.

8. Gawor J., Kornaś S., Charcenko V., Nowosad B., Skalska M.: Intestinal parasites and health problems in horses in different breeding systems. Med Weter 2006, 62, 331-334.

9. Gawor J.: Studies on small strongyles (Cyathostominae) and their eradication in riding horses with special reference to drug resistance. Thesis. Instytut Parazytologii im. Witolda Stefańskiego, Polska Akademia Nauk. Warszawa, 2006.

10. Kaplan R.M.: Drug resistance in nematodes of veterinary importance: a status report. Trends Parasitol 2004, 20, 477-481.

11. Knecht D., Popiołek M., Zaleśny G.: Does meatiness of pigs depend on the level of gastro-intestinal parasites infection? Prev Vet Med 2011, 99, 234-239.
12. Kornaś S., Cabaret J., Skalska M., Nowosad B.: Horse infection with intestinal helminths in relation to age, sex, access to grass and farm system. Vet Parasitol 2010, 174, 285-291.

13. Kornaś S., Skalska M., Nowosad B., Gawor J., Labaziewicz I., Babiuch A.: Occurrence of tapeworm, roundworm and botfly larvae in horses from southern Poland. Med Weter 2007, 63, 1373-1376.

14. Kornaś S., Skalska M., Nowosad B.: Seasonal dynamic of the occurrence of strongyles in horses in a stud. Med Weter 2008, 64, 1031-1033.

15. Lind E.O., Rautalinko E., Uggla A., Waller P.J., Morrison D.A., Höglund J.: Parasite control practices on Swedish horse farms. Acta Vet Scand 2007, 49, 25.

16. McKenna P.B.: The effect of previous cold storage on the subsequent recovery of infective third stage nematode larvae from sheep faeces. Vet Parasitol 1998, 80, $167-172$

17. Müller-Graf C.D.M., Woolhouse M.E.J., Packer C.: Epidemiology of an intestinal parasite (Spirometra spp.) in two populations of African lions (Panthera leo). Parasitology 1999, 118, 407-415.

18. Müller-Graf C.D.M.: A coprological survey of intestinal parasites of wild lions (Panthera leo) in the Serengeti and Ngorongo Crater, Tanzania, East Africa. J Parasitol 1995, 81, 812-814.

19. Nielsen M.K., Haaning N., Olsen S.N.: Strongyle egg sheeding consistency in horses on farms using selective therapy in Denmark. Vet Parasitol 2006, 135, 333-335.

20. Nielsen M.K., Vidyashankar A.N., Andersen U.V., DeLisi K., Pilegaard K., Kaplan R.M.: Effect of fecal collection and storage factors on strongylid egg counts in horses. Vet Parasitol 2010, 167, 55-61.

21. O'Grady M.R., Slocombe J.O.D.: An investigation of variables in a fecal flotation technique. Can J Comp Med 1980, 44, 148-154.

22. Pereckiene A., Kaziūnaite V., Vysniauskas A., Petkevicius S., Malakauskas A., Sarkūnas M., Taylor M.A.: A comparison of modifications of the McMaster method for the enumeration of Ascaris suum eggs in pig faecal samples. Vet Parasitol 2007, 149, 111-116.

23. Popiołek M., Szczęsna-Staśkiewicz J., Bartoszewicz M., Okarma H., Smalec B., Zalewski A.: Helminth parasites of an introducted invasive carnivora species, the raccoon (Procyon lotor L.), from the Warta Mouth National Park (Poland). J Parasitol 2011, 97, 357-360

24. Roepstorff A., Nansen P.: Epidemiology, diagnosis and control of helminth parasites of swine. FAO Animal Health Manual, Rome, 1998.

25. Rupasinghe D., Ogbourne C.P.: Laboratory studies on the effect of temperature on the development of the freeliving stages of some strongylid nematodes of the horse. Parasitol Res 1978, 55, 249-253.

26. Szczęsna J., Popiołek M., Schmidt K., Kowalczyk K.: Coprological study on helminth fauna in Eurasian Lynx (Lynx lynx) from the Białowieża Primeval Forest in eastern Poland. J Parasitol 2008, 94, 981-984.

27. Szczęsna J., Popiołek M.: The first record of Spirocerca lupi (Spirocercidae, Nematoda) in Poland based of faecal analysis of wolves (Canis lupus L.). Helminthologia 2007, 44, 230-232.

28. Vadlejch J., Petrtýl M., Zaichenko I., Cadková Z., Jankovská I., Langrová I., Moravec M.: Which McMaster egg counting technique is the most reliable? Parasitol Res 2011, 109, 1387-1394. 